\title{
SEMBLANZA DEL DR. VÍCTOR ML. SÁNCHEZ CORRALES
}

\author{
Jorge Antonio Leoni de León
}

\section{(요요}

Esta obra está bajo una licencia Creative Commons

Reconocimiento-No Comercial-Sin Obra Derivada 



\title{
SEMBLANZA DEL DR. VÍCTOR ML. SÁNCHEZ CORRALES \\ BIOGRAPHICAL SKETCH OF DR. VÍCTOR ML. SÁNCHEZ CORRALES
}

\author{
Jorge Antonio Leoni de León
}

\begin{abstract}
RESUMEN
La actividad académica del Dr. Víctor Ml. Sánchez Corrales abarcó todas las áreas en las que un universitario está llamado a desenvolverse. Destacado docente e investigador en los tres ejes del quehacer universitario (Docencia, Investigación y Acción Social), también se desempeñó de manera sobresaliente en numerosos cargos en la administración universitaria, de los que cabe resaltar su labor como miembro y Director del Consejo Universitario de la Universidad de Costa Rica, donde su visión de universidad dejó su impronta para las generaciones presentes y futuras.

Palabras clave: lexicografía, filología, romanística, lingüística, laudatoria, semblanza, Sánchez Corrales-Víctor Ml.
\end{abstract}

\begin{abstract}
The academic activity given by Dr. Víctor Ml. Sánchez Corrales encompasses all possible aspects for someone committed with the aims of Higher Education and its role in society. Accomplished professor and researcher in all the axes of university duties, he also carried out a large number of functions in the university administration. It is necessary to highlight his work as a Member and Director of the University Council of the University of Costa Rica, where his vision about the university's social, scientific, and educational roles left a remarkable impression for present and future generations.

Key words: lexicography, philology, romance studies, linguistics, biographical sketch, Sánchez Corrales-Víctor Ml.
\end{abstract}

"Nil sine magno vita labore dedit mortalibus"" Horacio (Libro I, Sátira IX, línea 59).

Ingreso a clase y veo a un hombre en traje entero, con una espesa barba negra, quien, con la mirada fija más allá de las paredes que nos contenían, nos abría un mundo hecho de sonidos, similitudes y diferencias, un mundo que no era otro que el de América, nuestro mundo,

Dr. Jorge Antonio Leoni de León. Universidad de Costa Rica. Profesor de la Escuela de Filología, Lingüística y Literatura. Costa Rica.

Correo electrónico: antonio.leoni@ucr.ac.cr

Recepción: 06- 02- 2014

Aceptación: 18- 03 - 2014 
visto a través de la herramienta que más nos distingue, nos une y nos separa, la lengua, la lengua española. Ese hombre era don Víctor Ml. Sánchez Corrales, don Víctor, en el curso de Español de América y Costa Rica, y esa imagen es la que aún conservo y atesoro, la de mi profesor, mi maestro, maestro de muchos, como ya tantas veces he oído decir. En aquel momento no sospechaba yo que esa materia constituiría uno de los pilares de mi formación, uno de esos temas que, a lo largo de los años, me correspondería visitar y revisitar, no como un pasatiempo, no como un punto de conversación de sobremesa, sino como un saber sobre el que he debido opinar y tomar decisiones como filólogo, como lingüista profesional, que era, para lo que al fin y al cabo, don Víctor nos preparaba.

Docencia, Conocimiento y Lenguaje son aspectos que confluyen en la obra de don Víctor

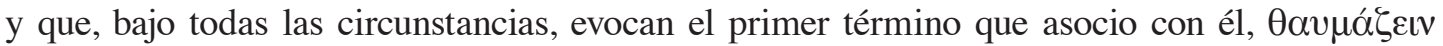
(thaumázein), el asombro griego, puesto en boca de Sócrates por Platón en el Teeteto: ${ }^{2}$ nuestra capacidad de asombro es correlacional con nuestra capacidad de conocer, de investigar, de elevarnos por encima de lo obvio y ampliar nuestros límites. Este asombro, que motiva su obra, él ha procurado transmitirlo a través de sus clases y sus conferencias. Un vistazo a sus primeros años de formación nos revela el origen de esta síntesis. De 1966 a 1975 él cursó Filología Española y Filosofía en la Universidad de Costa Rica, lo cual complementó con estudios de Posgrado en Lingüística en 1979. Los títulos de sus trabajos de licenciatura ilustran la amplitud de sus intereses: en Filología Española sustentó la tesis Estudio funcional del morfema modo en griego clásico (20 de enero de 1976), en Lingüística defendió el trabajo final de graduación $E l$ maleku haika: dos análisis fonológicos y gramática generativo-transformacional (30 de julio de 1976). El 28 de setiembre de 1982 obtiene el grado de Doctor en Filología, especialidad en Romanística, con la tesis Elementul lexical latin moştenit în spaniola şi româna en el Instituto de Lingüística de la Universidad de Bucarest, República Socialista de Rumanía, donde también fue Encargado de Negocios, Ministro Consejero y Cónsul General de Costa Rica (1981-1982).

Este recorrido pronosticaba, sin duda, un fructífero desempeño en Romanística y, ¿por qué no?, en Filología Clásica. Sin embargo, sus inquietudes, numerosas, lo llevaron a desarrollar una brillante carrera, en varios ámbitos académicos, que no dudo en calificar de total. Una ojeada a su currículum lo confirma: imparte Filosofía y Español como profesor en secundaria, mientras que, como docente universitario, prodiga sus enseñanzas en Gramática Española, Lingüística Románica, Dialectología Costarricense y Español de América y Costa Rica, solo por mencionar algunos cursos. Su labor no se limita a la Sede Rodrigo Facio, también colaboró en la Sede Regional de Occidente y en la Sede Regional del Atlántico, en las que tuvo a su cargo Español de América y Costa Rica y Gramática Histórica Española en los años 1992 y 1993 respectivamente. Su labor docente también germinó en el posgrado, donde destaco su participación en el Doctorado Latinoamericano en Educación (2006-2009) y su contribución en el Programa de Posgrado en Linguiística de la Universidad de Costa Rica, del que incluso también fue Director (1996-2000).

Su labor docente es complementada con una febril actividad en investigación, atestiguada por más de sesenta y seis artículos y ponencias sobre Romanística, Dialectología Costarricense, Lexicografía, Lingüística Aplicada, Lingüística Chibcha y Lingüística Clásica. Me permito citar solo algunos: ${ }^{3}$

a. "Herencia común y diferenciación léxicas latinas en la Romania lateral" (SánchezCorrales, 1984).

b. "Fricación de erre en el español de Costa Rica". (Sánchez-Corrales, 1985).

c. "Lexicografía del español en Costa Rica, visión crítica” (Sánchez-Corrales, 1988). 
d. "Lengua española en la educación costarricense. Redefinición” (Sánchez-Corrales, 1989).

e. "El legado lingüístico de Arturo Agüero Chaves" (Sánchez-Corrales, 1993).

f. "MA(J)E: de la denotación a la apelación, por los senderos de un costarriqueñismo" (Sánchez-Corrales, 2009).

g. "Comunicación de masa y emigración léxica: Del cine clásico mexicano a la conformación de la costarriqueñidad” (Sánchez-Corrales, 2010).

h. “¡Puta!, en el español de Costa Rica” (Sánchez-Corrales, 2011).

i. "Metáforas zoonímicas de humanos en el español de Costa Rica: caballo, yegua/burro, perro-perra, vaca y zorra. Estudio diferencial contrastivo" (Sánchez-Corrales, 2011).

j. "Del Jeep Willys a la llave Maya: marcas lexicalizadas en el español de Costa Rica" (Sánchez-Corrales, 2013).

Estoy seguro de que los presentes recordamos uno u otro de estos artículos, si no todos. Ellos destilan más que un saber erudito sobre la Lingüística y el Español de Costa Rica, ellos revelan una profunda preocupación por la identidad costarricense, concebida por don Víctor como multicultural y multilingüística. A partir de 1990, el quehacer en investigación de don Víctor está íntimamente ligado a su labor como lexicógrafo, la que ya se perfilaba en su tesis doctoral y que cristalizó en el Programa Estudios de Lexicografía HispánicoCostarricense $^{4}$ del Instituto de Investigaciones Lingüísticas (el cual, por cierto, él dirigió de 1998 a 2001). El ELEXHICÓS constituye, a mi parecer, un hito en la Historia de la Lingüística en Costa Rica. Es un ejemplo señero de realización académica con una gran cantidad tesis de grado y posgrado gestadas dentro del Programa e innumerables artículos, entrevistas e investigaciones interdisciplinarias. Pero, sobre todo, con una intención, ya muy arraigada, de preparar intelectual y profesionalmente a los futuros filólogos y lingüistas que, ¿por qué no decirlo?, se han diseminado con éxito por el mundo para profundizar los conocimientos, perfeccionar los métodos y pulir la rigurosidad adquiridos en el marco de las exigencias de la disciplina lexicográfica. Eso sí, esperamos todavía la pronta conclusión del anticipado "Nuevo Diccionario del Español de Costa Rica"; créanme, está en camino.

En este contexto se comprende bien su faceta como campesino. Su interés por la tierra no lo ha abandonado jamás y él nunca le ha dado la espalda a la noble actividad de sembrar y cosechar, dentro y fuera del ámbito académico. Aún recuerdo el café de su propia cosecha que un día tuvimos el placer de degustar o sus muchas anécdotas de la finca, a menudo entrelazadas con relatos de experiencias como cazador de palabras, viajero resignado o maestro comprensivo.

La Universidad de Costa Rica tiene tres ejes fundamentales: la Docencia, la Investigación y la Acción Social. Esto lo supe leyendo el Estatuto Orgánico de nuestra Universidad, pero lo aprendí de don Víctor. Él me enseñó que los conocimientos se comparten (Docencia), que los conocimientos se producen y se perfeccionan (Investigación) y que somos, como dicen en francés, redevables con la sociedad, es decir, que debemos hacer aportes tangibles al país, que también somos agentes de cambio (Acción Social). En consonancia con esta postura, Don Víctor fundó y dirigió el proyecto de TCU "Víctor Manuel Arroyo Soto", por medio del cual se ofrecía, principalmente, herramientas para mejorar el rendimiento académico de estudiantes de secundaria gracias a cursos remediales que también se extendieron a no videntes y personas de la tercera edad. 
No quiero que mi intervención se convierta en una simple relación de honores, cargos y anécdotas biográficas. Estos hechos están a la vista de todos, cualquier interesado puede leer su currículum vítae ${ }^{6}$ en línea o también puede conversar con él (es muy accesible). Mi intención es, más bien, mostrar la coherencia en el quehacer de don Víctor, coherencia que va más de allá de artículos, cursos, honores y cargos. Mi intención es revelar ese punto de convergencia, esa intersección de las relaciones equilibradas dentro del conjunto. ¿Dónde podemos hallar ese punto vélico, mencionado por Cortázar ${ }^{7}$ a propósito de Víctor Hugo, ese punto invisible que le da equilibrio al bote?

Podríamos pensar que lo encontramos en los ya tradicionales Coloquios Costarricenses de Lexicografía, los cuales forman parte de la larga trayectoria de don Víctor como expositor y organizador de eventos académicos nacionales e internacionales, abocados, claro está, a la difusión e intercambio del conocimiento. También podríamos mencionar, en este sentido, su labor editorial como Director de Káñina (desde 1996 hasta el presente) o su desempeño como Director de Escuela (en dos ocasiones, la última del 18 de abril de 1988 al 18 de abril de 1992). Incluso cabría referirnos a su merecidísimo nombramiento, en setiembre de 2012, como miembro de número de la Academia Costarricense de la Lengua, ${ }^{8}$ donde pasó a ocupar la silla "I" con el discurso "Guanacas(tequidad) o en torno al léxico del español de Guanacaste", respondido por el académico Mario Portilla Chaves, o su reciente emeritazgo en la Escuela de Filología, Lingüística y Literatura. No obstante no apunto ahí. Mi mirada está fija en su actividad como miembro del Consejo Universitario (de octubre de 2001 a octubre de 2005), del que además fue Director (del 16 de octubre de 2003 al 15 de octubre de 2004). Ahí descubro a don Víctor, el político universitario que debe poner al servicio de la Comunidad sus ideas y su visión sobre las estructuras que nos harán avanzar, ser mejores.

Me tomé la libertad de conversar con don Víctor a fin de comprender mejor sus ideas sobre la Universidad. De ese encuentro bosquejo su visión, que completa el cuadro de su quehacer académico. En esa discusión, don Víctor citó dos frases que a menudo le he escuchado citar y que marcaron un Norte en sus acciones y en sus iniciativas.

La primera frase es de Carlos Monge Alfaro, "La Educación: fragua de nuestra democracia"; 9 en ella, subsumido, podemos captar el concepto de universidad; así, para don Víctor, "la Universidad es fragua de nuestra democracia", es decir un espacio en el que la nación se inventa y se reinventa. Para don Víctor la Universidad es una institución basada en la excelencia académica y no en la clase social, que debe ser una opción de educación y desarrollo para promover un porvenir mejor, más equitativo. De ahí que los profesionales graduados de nuestra Institución deben tener un impacto positivo en la Familia y en la Sociedad.

La segunda frase, del Dr. Claudio Gutiérrez, "La Universidad, conciencia lúcida de la Patria", apunta a que la Universidad no establece políticas (nacionales), pero sí debe reflexionar sobre la sociedad en la que se desarrolla y también debe proporcionar los resultados de sus disquisiciones como insumos intelectuales, necesarios para el desarrollo. Así, por ejemplo, la Universidad está obligada a reflexionar sobre el Sistema de Salud y el Sistema de Educación, para los que debe diagnosticar problemas, proponer soluciones. Igualmente, en esta misma línea, cabría referirse al estado de la Red Vial Nacional y a la función que el Lanamme puede desempeñar.

Por consiguiente, don Víctor visualiza la Universidad como un espacio que promueve opciones de desarrollo nacional y de investigación, de donde nace la necesidad de formar recursos humanos de excelencia capaces de enfrentar los desafíos del Presente. 
Nunca ha creído él estar libre del error y a lo largo de su vida ha procurado mostrarse tolerante ante las diferencias y respetuoso de la formación académica rigurosa. Su bondad, de la que muchos podemos atestiguar, le hace comprender que si "la gente es buena, la institución es buena", porque la base de toda organización humana son las personas. Estaría incompleta esta semblanza si no mencionara dos de sus propuestas fundamentales:

a. El Perfil del profesor universitario, ${ }^{10}$ del cual aún se conversa en nuestra Comunidad y que ojalá sea retomado en algún momento por nuestras autoridades; y

b. El Centro de Formación Continua, el cual cristalizó, bajo otra forma, como la Red Institucional de Formación y Evaluación Docente (RIFED). ${ }^{11}$

Quiero insistir, Don Víctor, en dejar constancia de su calidad humana, su generosidad, su calidez como persona y su afán por propiciar que sus alumnos se superen constantemente. Aunque no puedo hablar por todos, sí puedo hacerlo a través de las generaciones que usted ha formado, por eso permítame, don Víctor, darle las gracias por todo; permítame manifestarle mi asombro por sus logros y, muy particularmente, por su humanidad: "Apa trece, pietrele rămân". ${ }^{2}$

\section{Notas}

1. Traducción: La vida no regala nada a los mortales sin un gran trabajo. [Fuente: http://data.perseus. org/].

2. "El asombro es un sentimiento filosófico, el verdadero inicio de la filosofía" Teeteto 155d [Fuente: http:// remacle.org/].

3. Fuentes en línea: http://revistas.ucr.ac.cr/index.php/kanina/ y http://www.latindex.ucr.ac.cr/kanina.php.

4. Por sus siglas, ELEXHICÓS.

5. Trabajo Comunal Universitario.

6. Currículum vítae en línea: http://www.lexicografia.ucr.ac.cr/

7. Cortázar (2007, p. 74).

8. Sitio web de la Academia Costarricense de la Lengua: http://www.acl.ac.cr/n_a.php?vsc

9. Monge-Alfaro y Rivas-Ríos (1978).

10. Fuente: http://boletin.cu.ucr.ac.cr/notas/08-2004/n14-804.html.

11. Sitio web del RIFED: http://www.rifed.ucr.ac.cr

12. En rumano: El agua fluye, las piedras permanecen.

\section{Bibliografía}

Cortázar, J. (2007). La Vuelta al Mundo en Ochenta Mundos. (Tomo 1). España: Siglo XXI Editores.

Monge-Alfaro, C. y Rivas-Ríos, F. (1978). La Educación: fragua de nuestra democracia. San José: Editorial Universidad de Costa Rica.

Sánchez-Corrales, V.M. (1984). Herencia común y diferenciación léxicas latinas en la Romania lateral. Revista de Filología y Lingüística de la Universidad de Costa Rica. 9 (2), 35-62.

Sánchez-Corrales, V.M. (1985). "Fricación de erre en el español de Costa Rica". Revista de Filología y Lingüística de la Universidad de Costa Rica. 11 (1), 63-66.

Sánchez-Corrales, V.M. (1988). Lexicografía del español en Costa Rica, visión crítica. Revista de Filología y Lingüística de la Universidad de Costa Rica. 14 (2), 147-156. [Edición 
en memoria de Primer Coloquio Germano-Hispanoamericano de Lexicografía del Español de América. Instituto Caro y Cuervo].

Sánchez-Corrales, V.M. (1989). Lengua española en la educación costarricense. Redefinición. Por C. Hernández et ál. (Eds.). El Español de América 3. Memoria del III Congreso Internacional de "El español de América". Valladolid-España. Salamanca: Gráficas Varona. (1211-1218). [Simultáneamente se publica en Revista de Filología y Lingüística de la Universidad de Costa Rica. 15 (2), 155-169].

Sánchez-Corrales, V.M. (1993). El legado lingüístico de Arturo Agüero Chaves. Por Y. SolanoRojas (Comp.). Memoria del V Congreso Filología y Lingüística "Prof. Arturo Agüero Chaves".San José: Editorial Guayacán Centroamericana. (39-42).

Sánchez-Corrales, V.M. (2009). MA(J)E: de la denotación a la apelación, por los senderos de un costarriqueñismo. Káñina. 33 (Especial), 33-43.

Sánchez-Corrales, V.M. (2010). Comunicación de masa y emigración léxica: Del cine clásico mexicano a la conformación de la costarriqueñidad. Káñina. 34 (Especial), 173-192.

Sánchez-Corrales, V.M. (2011). ¡Puta!, en el español de Costa Rica. Káñina. 35 (2), 83-86.

Sánchez-Corrales, V.M. (2011). Metáforas zoonímicas de humanos en el español de Costa Rica: caballo, yegua/burro, perro-perra, vaca y zorra. Estudio diferencial contrastivo. Káñina. 36 (Especial), 27-36.

Sánchez-Corrales, V.M. (2013). Del Jeep Willys a la llave Maya: marcas lexicalizadas en el español de Costa Rica. Káñina. 37 (1), 145-152. 